Tropical Journal of Pharmaceutical Research November 2015; 14 (11): 1969-1974

ISSN: $1596-5996$ (print); 1596-9827 (electronic)

(C) Pharmacotherapy Group, Faculty of Pharmacy, University of Benin, Benin City, 300001 Nigeria.

All rights reserved.

Available online at http://www.tjpr.org

Original Research Article

http://dx.doi.org/10.4314/tjpr.v14i11.3

\title{
Cytotoxic T-lymphocyte Antigen-4 Binding to SHP2 Interacting Transmembrane Adapter Protein by Phosphorylation in T-Cell
}

\author{
Sung-Kyu Lee and Hyun Kang* \\ Department of Medical Laboratory Science, College of Health Science, Dankook University, Cheonan-si, Chungnam, 330-714, \\ Republic of Korea \\ *For correspondence: Email: hyunbio@gmail.com, hkang@dankook.ac.kr; Tel: 82-41-550-1452; Fax: 82-41-559-7934
}

Received: 9 July 2015

Revised accepted: 11 October 2015

\begin{abstract}
Purpose: To investigate potential cytotoxic T-lymphocyte antigen-4 (CTLA-4) binding partners and assess whether potential binding partners affect the full function of CTLA-4.

Methods: The down-regulation effects of CTLA-4 and SIT were assessed by culturing CD3 stimulated T-cells. CTLA-4 and SIT proteins were measured by immunoblot analysis and production of interlukin-2 transcription activity evaluated by luciferase assay.

Results: CTLA-4 inhibited the interlukin-2 production capacity of CD3-stimulated T cells. CTLA-4 interaction with SHP2 interacting transmembrane adapter protein (SIT) in the down-regulation of the transcription of Interulin-2 required CTLA-4 binding to SIT tyrosine motifs. The SIT tyrosine mutants were significantly lower (25 - $75 \%$ ) after phosphorylation compared with WT-SIT (transfected cells, $p<$ 0.05 ) and untreated control. The remaining $90 \%$ phosphorylation in the F188ANS mutant can be explained by phosphorylation of other tyrosines in the sequence of SIT $(p<0.05)$. For interukin-2 transcription, F188ANS single mutant and double F148SEV mutant, increased NF-AT activity by $35 \%$ compared with the wild type $(p<0.05)$.

Conclusion: The findings imply that SIT transmembrane adaptor (SIT) protein, binds to CTLA-4 and thus potentiates the inhibitory role of this co-receptor. This phenomenon may lead to the development of new treatment strategies for autoimmune diseases and graft rejection.
\end{abstract}

Keywords: Cytotoxic T-lymphocyte antigen-4, Interleukin-2, Nuclear factor of activated T-cells/Activator protein-1, SHP2 interacting transmembrane adapter protein, Autoimmune diseases, Graft rejection

Tropical Journal of Pharmaceutical Research is indexed by Science Citation Index (SciSearch), Scopus, International Pharmaceutical Abstract, Chemical Abstracts, Embase, Index Copernicus, EBSCO, African Index Medicus, JournalSeek, Journal Citation Reports/Science Edition, Directory of Open Access Journals (DOAJ), African Journal Online, Bioline International, Open-J-Gate and Pharmacy Abstracts

\section{INTRODUCTION}

CTLA-4 signaling is well-documented in its ability to downregulate T-cell proliferation and cytokine production [1,2]. Studies using CTLA-4 antibodies have shown that CTLA-4 blocks T-cell proliferation, IL-2 production and NFAT translocation into the nucleus, implying that its general effects downplay the immune response [3]. An in vivo study of CTLA-4 knockout mice had tissue destruction by the immune system and extensive lymphadenopathy [4].

The full activation of naïve T-cells depends on two signals that ignite proliferation, differentiation and cytokine secretion [2]. The first is provided by the T-cell receptor (TcR) upon recognition of a specific antigenic peptide in complex with a MHC class II molecule. The second signal is delivered by the T-cell's co-stimulatory receptors upon ligation of their counterparts by antigen 
presenting cells (APC). The balance between signaling of the major co-stimulatory molecules CD28 (the positive co-receptor) and CTLA-4 (the negative co-receptor) determines the outcome of immune response [5].

Transmembrane adaptor proteins (TRAPS) facilitate precise signal transduction by forming specific protein complexes [5]. Unlike kinases, which use enzymatic and transcriptional activity to promote signaling, TRAPS act as scaffolds and recruit molecules for detailed intracellular signaling complexes [6]. Recently, our laboratory found that a small TRAP, SIT, binds to CTLA-4 and enhances CTLA-4 surface expression [6]. SIT is a disulfide-linked homodimeric polypeptide which is exclusively expressed in lymphocytes. In contrast to the other transmembrane adaptor proteins known so far, SIT is a heavily glycosylated polypeptide [13]. This could indicate that SIT possesses an external ligand that modulates its function. This study was conducted to understand the molecular mechanisms leading to tyrosine phosphorylation of CTLA4/SIT complex.

\section{EXPERIMENTAL}

\section{Cells and reagents}

Jurkat T-cells (ATCC, American Type Culture Collection, VA, USA ) were cultured in RPMI 1640 supplemented with $5 \%$ fetal calf serum (FCS), $2 \mathrm{mM}$ L-glutamine and $100 \mathrm{U} / \mathrm{ml}$ penicillin/streptomycin [7]. Anti-CD3 (OKT3) was obtained from the ATCC and anti-human CTLA-4 mAb was provided by Dr. Broeker (Greifswald, Germany). Anti-HA antibody was purchased from Covance Research Product Inc.

\section{Plasmid DNA cloning}

Full-length human SIT-R CDNA PCR primer sequences were 5-gctctagagccaccatg-3 sense and 5-tgacacgccaagcttggtac-3 antisense. PCR contained five cycles of $60 \mathrm{~s}$ at $94{ }^{\circ} \mathrm{C}, 30 \mathrm{~s}$ at 37 ${ }^{\circ} \mathrm{C}$ and $60 \mathrm{~s}$ at $72{ }^{\circ} \mathrm{C}$ and a further 25 cycles within an annealing temperature of $45^{\circ} \mathrm{C}$. The amplified products were ligated into the TA cloning vector (Invitrogen) and confirmed by DNA sequencing.

\section{Immunoprecipitation and immunoblotting}

Cells were lysed in an ice-cold lysis buffer containing $1 \%$ Triton $\mathrm{X}-100$ in $20 \mathrm{mM}$ Tris- $\mathrm{HCl}$, $\mathrm{pH}$ 8.3, $150 \mathrm{mM} \mathrm{NaCl}$, protease inhibitors, and phosphatase inhibitors. Post-nuclear lysates were incubated for $1 \mathrm{~h}$ with the indicated antibody. Protein A-Sepharose beads $(30 \mu \mathrm{l}$, Amersham Pharmacia) were added and incubated for $1 \mathrm{~h}$ at $4^{\circ} \mathrm{C}$. The eluted proteins were separated by $10 \%$ SDS-PAGE and transferred to a nitrocellulose membrane for immunoblotting. The membranes were blocked with $5 \%$ milk in TBS $(10 \mathrm{mM}$ Tris- $\mathrm{HCl}, \mathrm{pH} 7.6$, $150 \mathrm{mM} \mathrm{NaCl}$ ) and incubated with their corresponding antibodies. A secondary antibody, provided by Amersham (NJ, USA), allowed the first antibody to be observed by enhanced chemiluminescence (ECL).

\section{Interleukin-2 luciferase assay}

Jurkat T-cells were co-transfected with $10 \mu \mathrm{g}$ of corresponding cDNA and combined with $2 \mu \mathrm{g}$ of pNFAT3-Luc plasmid or $0.1 \mu \mathrm{g}$ of a control reporter plasmid ( $\mathrm{pRL}-\mathrm{TK}$ from Promega). Cells were pulsed using BTX Gene Pulser at $260 \mathrm{~V}$, $960 \mathrm{~F}$ in $10 \%$ Fetal Calf Serum. Cells $\left(1 \times 10^{7}\right.$ cells) were aliquoted in a 96-well plate $18 \mathrm{hrs}$ after transfection and cultured in a final volume of $200 \mu \mathrm{L}$ of RPMI 1640 growth medium. After $5 \mathrm{~h}$ stimulation by CD3 $(145-2 \mathrm{C} 11 ; 2 \mu \mathrm{g} / \mathrm{mL})$, CD3/rabbit anti-mouse $(2 \mu \mathrm{g} / \mathrm{mL})$ antibodies, or rabbit anti-mouse antibodies alone (which served as negative controls), cells were lysed in $100 \mu \mathrm{L}$ of lysis buffer (Promega kit, Promega, WI, USA). Luciferase activity was quantified using a luminometer (MicroLumat, EG7G Berthold) immediately after addition of $100 \mu \mathrm{L}$ luciferase substrate (Promega kit) and a Stop and Go reaction to control amounts of reporter plasmid (dual luciferase system kit from Promega, WI, USA). Luciferase units of the experimental vector were normalized to the level of the control vector in each sample.

\section{Statistical analysis}

Data are presented as mean \pm SEM $(n=3)$. Statistical analysis was performed with a statistical software (SAS Institute, Cray, NC, USA) using one-way analysis of variance, followed by Dunnett's multiple range tests. $P<$ 0.05 was considered statistically significant.

\section{RESULTS}

\section{Identification of the SIT tyrosine phosphorylation}

Fig $1 \mathrm{~A}$ shows the amino acid sequence of a portion the potential tyrosine phosphorylation motifs that would be suited for $\mathrm{SH} 2$ domain binding. The cytoplasmic domain of SIT carries a total of five potential sites of tyrosine phosphorylation. These are $\mathrm{Y}^{90} \mathrm{GNL}, \mathrm{Y}^{128} \mathrm{TSL}$, $\mathrm{Y}^{148} \mathrm{SEV}, \quad \mathrm{Y}^{168} \mathrm{ASV}$ and $\mathrm{Y}^{188} \mathrm{ANS}$. To assess 
which of these five tyrosines represent phosphorylation sites, we generated a series of SIT mutants.

To determine whether the tyrosine base motifs are sites of phosphorylation, wild-type SIT (WT SIT) and SIT mutants were expressed in Jurkat T cells, the cell were activated 2 min with pervanadate and were assessed for phosphorylation by anti-phosphotyrosine blotting (Fig. 1B, upper panel). The $\mathrm{F}^{90} \mathrm{GNL}$ and $\mathrm{F}^{168} \mathrm{ASV}$ single mutants were significantly less phosphorylated when compared with WT SIT (lane 3 and 6 vs 2). Phosphorylation was reduced even further (generally $<90 \%$ of WT) in the $\mathrm{F}^{188} \mathrm{ANS}$ (lane 7; also see histogram in Fig. 1C). As an internal control for expression, antiSIT Ab detected similar levels of expression for SIT and the mutants (Fig. 1B, lower panel). These data demonstrate that $\mathrm{F}^{90} \mathrm{GNL}, \mathrm{F}^{168} \mathrm{ASV}$ and $\mathrm{F}^{188} \mathrm{ANS}$ are major sites of phosphorylation by pervanadate. The remaining $90 \%$ phosphorylation in the $\mathrm{F}^{188}$ ANS mutant can be explained by protein tyrosine kinase phosphorylation of other tyrosines in the sequence of SIT.

\section{SIT tyrosine based motifs are necessary for CTLA-4 binding}

To assess whether the tyrosine sites are responsible for binding to CTLA-4, the SIT mutants $\left(\mathrm{F}^{90} \mathrm{GNL}, \mathrm{F}^{128} \mathrm{TSL}, \mathrm{F}^{148} \mathrm{SEV}, \mathrm{F}^{168} \mathrm{ASV}\right.$ and $\mathrm{F}^{188} \mathrm{ANS}$ ) were co-expressed with CTLA-4 in Jurkat $T$ cells followed by immuno-precipitation with anti-CTLA Ab and anti-SIT blotting. The expression levels of SIT and the mutants and CTLA-4 were similar as shown in the whole-cell lysates (Fig. 2A, right upper and lower panels, respectively). As expected, CTLA-4 coprecipitated WT SIT (left panel, lane 1), whereas the mutant $F^{90} \mathrm{GNL}, \mathrm{F}^{148} \mathrm{SEV}, \mathrm{F}^{188} \mathrm{ANS}$ fail to coprecipitate with CTLA-4.

The single mutations resulted in significant reductions in CTLA-4 binding, with $\mathrm{Y}^{188}$ ANS having a greater effect (90\% reduction) than $\mathrm{Y}^{148} \mathrm{SEV}(85 \%$ reduction) (left panel, lanes 5 and 6 also see Fig 2B: densiometric readings in histogram).

A

MNQADPRLRAVCLWTLTSAAMSRGDNCTDLLALGIPSITQA WGLWVLLGAVTLLFLISLAAHLSQWTRGR SRSHPGQGRSGESVEEVPLY ${ }^{90}$ GNLHYLQTGRLSQDPEPDQQDPTLGGPARAAEEVMCY ${ }^{128}$ TSLQLRPP QGRIPGPGTPVKY ${ }^{148}$ SEVVLDSEPKSQASGPEPELY168 ASVCAQTRRARASFPDQA Y ${ }^{188}$ ANSQPAAS

B

C Relative Phosphorylation
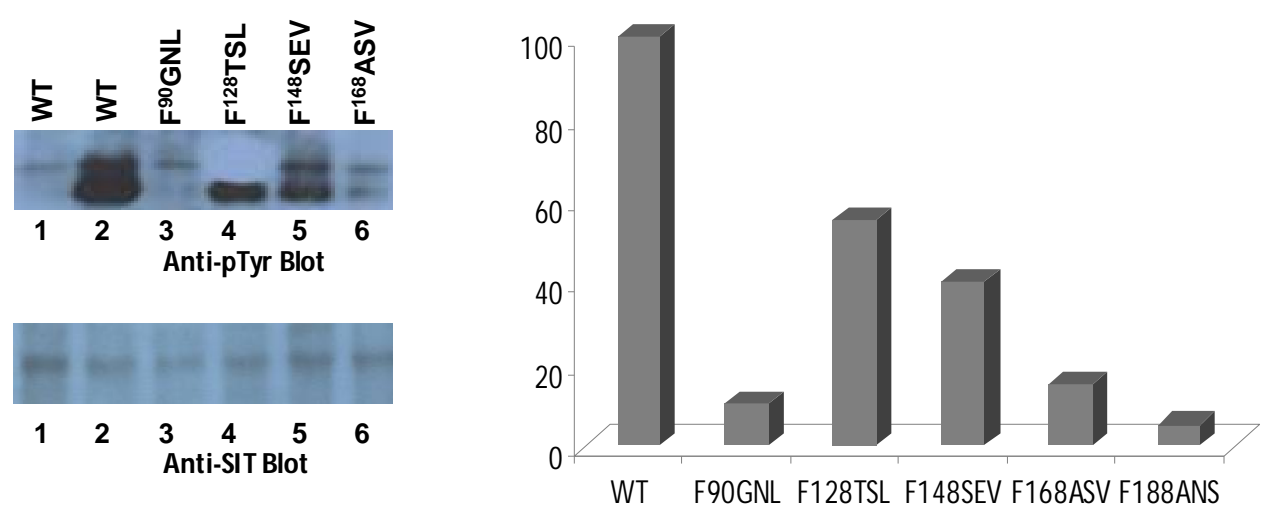

Figure 1: Identification of major sites of SIT phosphorylation by pervanadate in T cell. The tyrosines 128 and 148 are phosphorylated by pervanadate in Jurkat cells. $A=$ The mutants of SIT created for these studies with phenylalanine $(F)$ replacing tyrosine $(Y)$ in the underlined region. $B=$ CDNA wild type SIT (lanes 1 and 2) and SIT mutants (lanes 3-6) were transfected alone into Jurkat cells. Then, $18 \mathrm{~h}$ after transfection, lysates were prepared in 1\% Triton X-100 lysis buffer, subjected to SDS-PAGE, and immunoblotted with anti-pTyr Ab (upper panel) or anti-SIT Ab (lower panel). Positions of molecular mass markers (kDa) are indicated. C, Densitometric analysis using the Scantjet laser scanner (Hewlett-Packard) of anti-pTyr binding to SIT (B, upper panel). Values were standardized with anti-SIT binding to SIT (B, lower panel). The data were normalized tothe control cells. Data are expressed as the mean \pm SD $(n=5)$. Transfected cells $(p<0.05)$ compared to untreated control 
SIT and CTLA-4 interaction is required to downregulate IL-2 transcription activity

To address the role of CTLA-4 binding to SIT in T cell function, Jurkat $T$ cells were transiently transfected with SIT mutants or a control vector together with CTLA-4 and a luciferase reporter construct driven by an IL-2 NF-AT/AP-1 promoter. The combined expression of $\mathrm{F}^{188} \mathrm{ANS}$ SIT mutant /CTLA-4 potentiated IL-2 transcription by about 35 -fold beyond vector-transfected control (Fig 3).

A

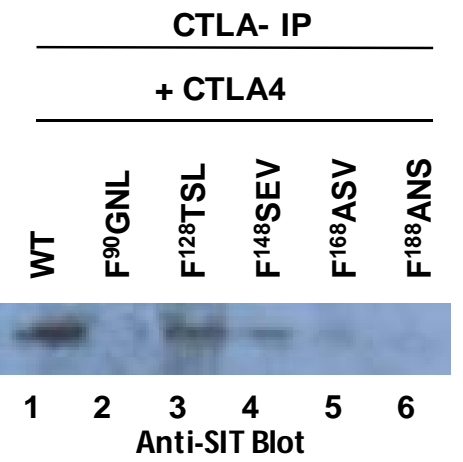

B

Relative Binding

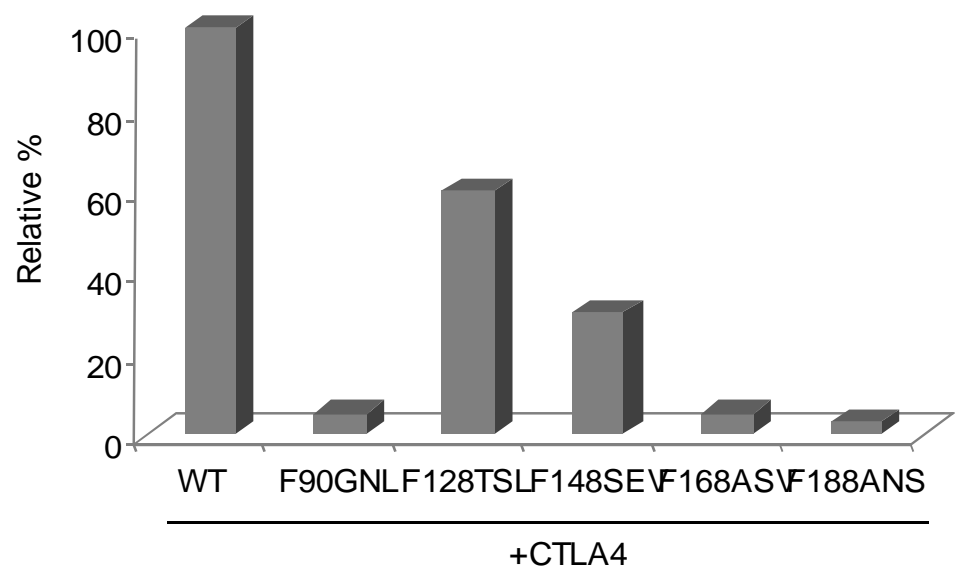

Figure 2: (A) Comparison binding analysis of = SIT mutants with CTLA-4. Then, $18 \mathrm{~h}$ after transfection, cells were lysed and precipitated with anti-SIT Ab. Anti-SLP-76 immune complexes (lanes 1-6) and cell lysates (A. left pannel, lanes 1-6) and were subjected to SDS-PAGE and blotted with anti-SIT and anti-CTLA-4. Positions of molecular mass markers $(\mathrm{kDa})$ are indicated. Lanes 1 , cells transfected with WT SIT; lanes 2, $\mathrm{F}^{90} \mathrm{GNL}$; lanes 3 , $\mathrm{F}^{128} \mathrm{TSL}$; lanes 4, $\mathrm{F}^{148} \mathrm{SEV}$; lanes $5, \mathrm{~F}^{168} \mathrm{ASV}$; lanes $6, \mathrm{~F}^{188} \mathrm{ANS}$. (B) Densitometric analysis using the Scantjet laser scanner (Hewlett-Packard) of SIT bound to CTLA-4 (A, left panel). The data were normalized to the control cells. Data are expressed as the mean $\pm \operatorname{SD}(n=5)$. Transfected cells $(p<0.05)$ compared to untreated control 
The enhancing was greatest with the $\mathrm{F}^{188}$ ANS single mutant and the double $\mathrm{F}^{148} \mathrm{SEV}$ mutant, enhancing the NF-AT activity by 30-35\% compared with the wild type (Fig 3).

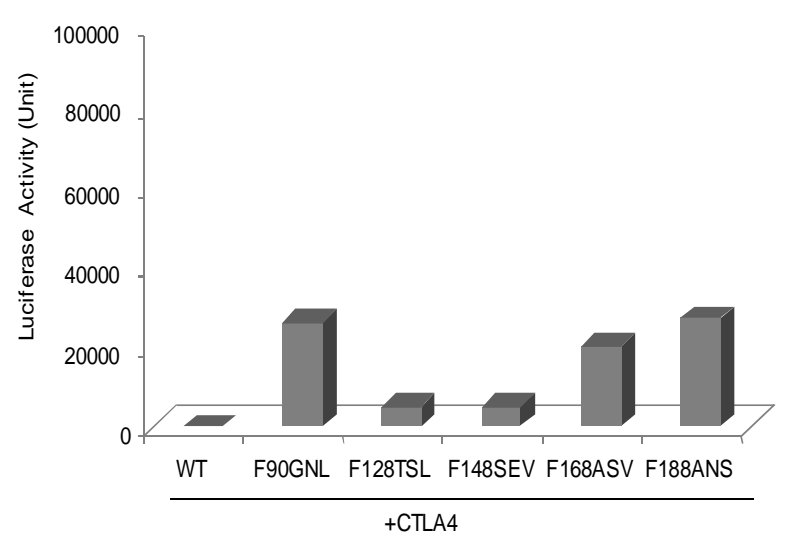

Figure 3: CTLA-4/SIT-R complex completely inhibited IL-2 gene transcription. Luciferase units of the experimental vector were normalized to the level of the control plasmid in each sample. The data were normalized to the control cells. Data are expressed as the mean $\pm S D(n=5)$. Transfected cells $(p<0.05)$ compared to untreated control

\section{DISCUSSION}

CTLA-4 plays an important role in mediating Tcell function, but little is known regarding the mechanisms behind this response. Thus, a better understanding of the molecular mechanism of CTLA-4 will allow researchers to develop therapeutic approaches to reverse the adverse impact of CTLA-4 dysfunction and harness the immune response.

Reported mechanisms include competition for CD28 binding to CD80 and CD86 [8], disruption of CD28 localization at the immunological synapse [9], binding to phosphatases PP2A and SHP-2 and interference with lipid raft expression [10]. In contrast to CD28, which is found on resting and activated cells, CTLA-4 is only found on activated cells. It is primarily an intracellular antigen whose surface expression is tightly regulated [11]. This tight regulation is achieved by controlled trafficking to the cell surface and rapid internalization. Even at its highest amounts, surface expression of CTLA-4 is only at about 3 percent of the time CD28 (the positive coreceptor) is expressed [12].

During the past few years, several TRAPs involved in the relay signaling have been identified including LAT (linker for activation of Tcells), SIT (SHP2 interacting transmembrane adaptor protein), LAX (Ick interacting membrane protein), LIME (Ick interacting membrane protein), NTAL/LAB (T-cell activation linker/linker for activation of B-cells) and PAG/Cbp (phosphoprotein associated with glycosphingolipid-enriched microdomains/CSK binding protein) [13]. Recently, the small transmembrane adaptor protein $T$ cell receptorinteracting molecule (TRIM) was found to bind to CTLA-4 leading to enhanced CTLA-4 surface expression [7].

SIT-R is capable of binding to CTLA-4 in T-cell. This identification of SIT binding to CTLA-4 increases the number of proteins known to bind CTLA-4, and possibly suggests that SIT and SIT$R$ will act in a negative signaling cascade. From our observations, it appears that in T cells both $\mathrm{Tyr}^{148}$ and $\mathrm{Tyr}^{188}$ are essential for optimal binding of CTLA-4.

The regulation of CTLA-4 function by interaction with SIT may serve as a possible accessory immunomodulatory molecule for optimizing T-cell function. In addition, the absence of CTLA-4 has been shown to result in organ destruction, lymphoproliferative disease and numerous autoimmune diseases in human including diabetes. On the contrary, an excessive decrease in T-cell mediated immune reaction by CTLA-4/SIT complex leads to chronic infection.

\section{CONCLUSION}

The findings of this study show that TRAP, termed SIT transmembrane adaptor (SIT) protein, binds to CTLA-4 and potentiates the inhibitory role of this co-receptor. SIT-R plays an important role in the functions of CTLA-4, and hence, extensive studies of its properties in vivo is required.

\section{ACKNOWLEDGEMENT}

This research was supported by a grant from the Basic Science Research Program through the National Research Foundation of Korea (NRF) funded by Korean Ministry of Education, Science and Technology (no. 2010-0025105).

\section{REFERENCES}

1. Linsley PS. Distinct roles for CD28 and cytotoxic $T$ lymphocyte-associated molecule-4 receptors during $T$ cell activation. J ExpMed1995;182: 289-292.

2. Bluestone JA, Lechler RI. Transplantation. Curr Opin Immunol 1995; 7: 617-619.

3. Walunas $T L$, Lenschow DJ, Bakker CY, Linsley PS, Freeman GJ, Green JM, Thompson CB, Bluestone 
JA. CTLA-4 can function as a negative regulator of $T$ cell activation. Immunity 1994; 1: 405-413.

4. Tivol EA, Borriello $F$, Schweitzer AN, Lynch WP, Bluestone JA, Sharpe AH. Loss of CTLA-4 leads to massive lymphoproliferation and fatal multiorgan tissue destruction, revealing a critical negative regulatory role of CTLA-4. Immunity 1995; 3: 541547.

5. Samelson LE. Signal transduction mediated by the $T$ cell antigen receptor: the role of adapter proteins. Annu. Rev. Immunol 2002; 20: 371-394.

6. Simeoni L, Lindquist JA, Smida $M$, Witte $V$, Arndt $B$, Schraven $B$. Control of lymphocyte development and activation by negative regulatory transmembrane adapter proteins. Immunol Rev 2008; 224: 215-228.

7. Valk E, Leung $R$, Kang $H$, Kaneko K, Rudd CE, Schneider $H$. $T$ cell receptor-interacting molecule acts as a chaperone to modulate surface expression of the CTLA-4 coreceptor. Immunity 2006; 25: 807-821.

8. Masteller EL, Chuang E, Mullen AC, Reiner SL, Thompson CB. Structural analysis of CTLA-4 function in vivo. J Immunol 2000; 164: 5319-5327.

9. Lee KM, Chuang E, Griffin M, Khattri R, Hong DK, Zhang $W$, Straus $D$, Samelson $L E$, Thompson $C B$,
Bluestone JA. Molecular basis of T cell inactivation by CTLA-4. Sci 1998; 282: 2263-2266.

10. Chikuma S, Bluestone JA. CTLA-4 and tolerance: the biochemical point of view. Immunol Res 2003; 28: 241-253.

11. Alegre ML, Noel PJ, Eisfelder BJ, Chuang E, Clark MR, Reiner SL, Thompson CB. Regulation of surface and intracellular expression of CTLA4 on mouse $T$ cells. $J$ Immunol 1996; 157: 4762-4770.

12. Lindsten T, Lee KP, Harris ES, Petryniak B, Craighead N, Reynolds PJ, Lombard DB, Freeman GJ, Nadler LM, Gray GS. Characterization of CTLA-4 structure and expression on human T cells. J Immunol 1993; 151: 3489-3499.

13. Simeoni L, Lindquist JA, Smida $M$, Witte $V$, Arndt $B$, Schraven B. Control of lymphocyte development and activation by negative regulatory transmembrane adapter proteins. Immunol Rev 2008; 224: 215-228.

14. Chambers CA, Kuhns MS, Egen JG, Allison JP. CTLA-4mediated inhibition in regulation of $T$ cell responses: mechanisms and manipulation in tumor immunotherapy. Annu Rev Immunol 2001; 19: 565594. 